\title{
AS EMOÇÕES E A TRANSMISSÃO LINGUÚSTICA INTERGERACIONAL: UM ESTUDO DE CASO
}

\author{
EMOTIONS AND INTERGENERATIONAL LINGUISTIC TRANSMISSION: \\ A CASE STUDY
}

\author{
Mario Luis Monachesi Gaio | Lattes | mlmgaio@id.uff.br \\ Universidade Federal Fluminense $\mid$ Europa-Universität Viadrina
}

Resumo: Desde meados do século XIX, as línguas de imigração passaram a fazer parte de muitas sociedades no Brasil. Apesar de pressões nacionalistas, a transmissão linguística intergeracional conseguiu dar sobrevida a algumas dessas línguas, sobretudo pelo seu apelo emocional nos ambientes mais íntimos. Com base nos estudos sobre a relação entre língua e emoção (AVERILL, 1982; HARKINS; WIERZBICKA, 2001; DEWAELE; PAVLENKO, 2002; DEWAELE, 2013; PAVLENKO, 2012), apresentamos um estudo de caso que exemplifica uma situação real de transmissão lexical motivada por emoção. Durante um empreendimento comum, o deslocamento de uma casa de madeira, um grupo de pessoas conversa entre si em uma variedade do Português Brasileiro (PB) influenciada por traços da língua vêneta. Quando algo de errado acontece, as emoções afloram e o protagonista da cena pragueja na língua de seus ancestrais, numa demonstração de que práticas linguísticas podem permanecer no seio de comunidades de descendentes de imigrantes, mesmo que a língua tenha sofrido o processo de language shift ${ }^{1}$, e que tais práticas têm maior probabilidade de se manifestar se motivadas por momentos que evocam emoção.

Palavras-chave: Contato de línguas; Línguas de imigração; Imigração italiana no Brasil; Emoções na língua.

\begin{abstract}
Since mid-nineteenth century, immigration languages have become part of many societies in Brazil. Despite nationalist pressures, intergenerational language transmission managed to help some of them to survive, especially by its emotional appeal in intimate environment. Supported on studies on the relationship between language and emotion (AVERILL, 1982; HARKINS; WIERZBICKA, 2001; DEWAELE; PAVLENKO, 2002; DEWAELE, 2013; PAVLENKO, 2012), we present a case study that

\footnotetext{
${ }^{1}$ No âmbito dos estudos de línguas em contato, language shift é o processo de substituição do uso de uma língua por outra. Frequentemente a língua substituída é a de menor prestígio.
} 
illustrates a real situation of lexical transmission driven by emotion. During a common enterprise, the displacement of a wooden house, a group of people talk in a Brazilian Portuguese (PB) variety influenced by traits of the Venetian language. At some point, something goes wrong and emotions arise. The protagonist starts cursing in his ancestors' language, demonstrating that linguistic practices can remain within communities of immigrant descendant, even if the language has undergone the process of language shift, and that such practices are more likely to be manifested if they are motivated by moments that evoke emotion.

Keywords: Language contact; Immigration language; Italian immigration in Brazil; Emotions in language.

\section{Introdução}

A identidade nacional brasileira é formada por populações autóctones, africanos, europeus, asiáticos e por povos do Oriente Médio, diferentemente do que tenta nos fazer crer a "fábula das três raças²". Se é verdade que, até meados do século XIX, o povo brasileiro, de modo geral, era constituído por portugueses, africanos e populações autóctones, a partir dos movimentos migratórios da Europa, Ásia e Oriente Médio, essa configuração sofreu alterações significantes. Burke (2009) nos mostra duas definições distintas acerca da formação do povo brasileiro que atestam essa mudança: o explorador Karl von Martius (1794-1868) diz que "a história do Brasil poderia ser escrita em termos de fusão de três raças". Já o sociólogo Gilberto Freyre (1900-1987) falava da "fusão harmoniosa de tradições diversas”. A história do Brasil é marcada pelo constante deslocamento de pessoas, seja forçado ou voluntário. O país constitui-se como uma sociedade multiétnica em virtude desse movimento de pessoas de origens e culturas (e línguas, devemos acrescentar) diferentes e distantes (CROCI, 2011).

A História nos mostra o quanto os governantes receiam que seus governados falem outras línguas que não a nacional. Proibições, retaliações, negações sempre fizeram parte da vida de grupos linguísticos minoritários. No caso brasileiro, citamos dois eventos marcantes: a proibição do uso da Língua Geral, medida imposta pelo Marquês de Pombal em 1757 para forçar o uso do português, e a Campanha de Nacionalização, promovida pelo Estado Novo, de Vargas, na década de 1930. Obrigar as pessoas a falarem uma língua

\footnotetext{
2 A fábula das três raças prega a ideia de que o povo brasileiro é formado pela miscigenação entre os brancos (portugueses), os negros e os índios. Não considera a importância dos imigrantes de outros países europeus, asiáticos e médio-orientais (Cf. CROCI, 2011).
} 
que não as deixa à vontade pode funcionar em determinados ambientes comunicativos (SAVEDRA, 1994; 2009), mas dificilmente esse cerceamento vai ter êxito nos ambientes mais íntimos dos indivíduos, tais como o seio familiar. Para o falante, palavras carinhosas têm mais força se ditas na sua $\mathrm{L}^{3}$, mas como pode influenciar o ouvinte? Expressões orais de alegria ou de raiva estão relacionadas a emoções momentâneas que sentimos, e é natural associarmos esses momentos emocionantes a expressões linguísticas que ouvimos ao longo de nossas vidas. Quando tais expressões não fazem parte da L1 de um grupo social, mas permanecem sendo usadas pelos seus membros, temos então uma evidência da influência da emoção na transmissão linguística intergeracional.

Neste artigo, discorreremos sobre traços de língua de imigração transmitidos às gerações posteriores motivados por momentos de emoção. Trata-se de um estudo de caso entre descendentes de imigrantes italianos. O tema "língua e emoção" é parte da tese de doutoramento do autor, cuja pesquisa aprofunda os estudos de contato linguístico e cultural de imigração italiana no Brasil.

\section{Língua e emoção}

A relação entre língua e emoção, objeto de estudo de psicanalistas desde Freud, ainda permanece sub-teorizada e sub-pesquisada nos estudos de multilinguismo, como aponta Pavlenko (2012). Pacientes bi/multilíngues costumam apresentar diferentes personalidades nas suas respectivas línguas, e uma característica é bem recorrente: A L1 está comumente presente na origem das ansiedades mais profundas, ao passo que as demais línguas por eles faladas ou usadas funcionam como um distanciador de experiências traumáticas (PAVLENKO, 2012). Em outras palavras, a L1 está ligada intrinsecamente aos sentimentos mais íntimos.

"Emotions constitute an intrinsic part of our language attitudes and linguistic interaction and yet they have remained under-researched and undertheorized in the field of multilingualism."4 (PAVLENKO, 2012, p. 454). A mesma autora aponta para estudos interlinguísticos que demonstram diferenças entre línguas acerca do tamanho do léxico dedicado a emoção, das categorias morfossintáticas usadas para expressar emoções, e também da organização conceitual no domínio da emoção. Isso reflete importantes diferenças culturais que guiam esse domínio nas diversas sociedades. Por essa razão, Dewaele (2013) faz uma crítica aos estudos cognitivos acerca das emoções, vistos como universais, mas predominantemente realizados em ambientes anglófonos.

\footnotetext{
${ }^{3}$ Optamos pelo uso da nomenclatura L1, L2 etc. para nos referirmos às línguas faladas por indivíduos bi/ multilíngues, considerando L1 a primeira língua do indivíduo ou a que lhe transmite maior segurança, às vezes chamada de língua materna.

${ }^{4}$ Emoções constituem uma parte intrínseca de nossas atitudes linguísticas e de interação. (As traduções ao longo deste trabalho são de nossa responsabilidade).
} 
Tomando como exemplo o sentimento de raiva e as áreas do cérebro que são por ele afetadas, estudiosos admitem que emoções sejam ligadas a processos fisiológicos, mas ressaltam a importância de que estudos sobre emoções abarquem informações provenientes de várias línguas. A esse respeito, afirmam Harkins e Wierzbicka (2001, p. 2-3): "Whatever the conditions that produce an emotion like anger, whether or not it is visibly expressed, and whatever physiological responses accompany it, it is only through language (if at all) that we can know that what is experienced is anger."

Os vocábulos relacionados às emoções, as "emotion words", refletem e transmitem determinados modelos culturais, que, por sua vez, refletem e transmitem parâmetros de referência da sociedade ou comunidade de fala de onde surgiram e se desenvolveram (WIERZBICKA; HARKINS, 2001). De forma mais abrangente, uma análise diacrônica pode demonstrar que o significado das emotion words muda ao longo do tempo, como apontam Wierzbicka e Harkins (2001). Não existe, portanto, um conceito completamente desapegado de cultura (culture-free). Os mesmos autores nos mostram que o léxico é apenas um dos itens que nos ajudam a identificar pistas que nos levam ao "universo emocional da cultura"'. A gramática, o modo de se construir uma oração ou um período, a prosódia, as interjeições, os xingamentos, as formas de se dirigir a alguém, a linguagem corporal, a linguagem multimodal, enfim, nos oferece boas pistas para rastrear as emoções manifestadas pelos indivíduos. E queremos chamar particular atenção para os xingamentos, que costumam vir do âmago do indivíduo.

Dewaele (2013) se vale de conceitos de Averill (1982) para apontar a importância do meio social na avaliação das emoções. Segundo este último (p. 19), a atribuição da emoção dependeria de seu papel dentro de um sistema mais amplo de comportamento, começando pelo nível social: "[...] most emotions [...] reflect the thought of an epoch, the secret of a civilization." ${ }^{8}$ E complementa: "[... ] to understand the meaning of an emotion is to understand the relevant aspects of the sociocultural system of which the emotion is a part." (p. 24).

Recentes estudos sobre a relação entre multilinguismo e emoções demonstram que falantes preferem a sua L1 para externar emoções, sejam elas positivas (felicidade, satisfa-

\footnotetext{
${ }^{5}$ Sejam quais forem as condições que produzem uma emoção como a raiva, seja ela visivelmente expressa ou não, e sejam quais forem as respostas fisiológicas que a acompanham, é somente através da língua (...) que podemos reconhecer que o que está sendo experenciado é raiva.

${ }^{6}$ Por simplificação, doravante adotaremos essa expressão em inglês em referência a "vocábulos relacionados a emoções".

${ }^{7}$ Emotional universe of culture, expressão usada por Wierzbicka e Harkins (2001).

8 [...] muitos sentimentos de emoção [...] refletem o pensamento de uma era, o segredo de uma civilização.

9 [...] entender o significado de uma emoção é entender os aspectos relevantes de um sistema sociocultural, do qual a emoção faz parte.
} 
ção) ou negativas (raiva, angústia). Pavlenko (2012) evidencia diversas situações em que a L1 se sobressai nos momentos emotivos. Apenas para citar alguns exemplos, há escritores bilíngues que preferem escrever em sua L1 e pais que afirmam que só conseguem criar conexão emocional com os filhos nas suas L1.

Quando os pais criam os filhos em L2, o code-switching acontece em situações de emoção. As palavras de carinho usadas para se dirigir aos cônjuges ou aos filhos via de regra fazem parte do vernáculo de L1. Além disso,

\begin{abstract}
Individuals who remain dominant in their $\mathrm{L} 1$ and perceive it as most emotional may also spontaneously revert to $\mathrm{L} 1$ to argue with spouses and partners, to scold and discipline their children, and to use taboo and swearwords to maximum effect and satisfaction. (DEWAELE, 2004a, 2004b, 2006; PAVLENKO, 2004, 2005, 2008a apud PAVLENKO, 2012, p. 461, grifo nosso). ${ }^{10}$
\end{abstract}

Como observamos até este momento, estamos sempre considerando a condição de bi/multilinguismo como não balanceada, isto é, com uma L1 tratada como língua nativa (ou materna, como aceita pelo senso comum) e as demais como línguas secundárias. É importante frisar esse ponto porque a condição de bi/multilíngue que leva em conta somente os falantes cujo domínio de mais de uma língua é igual e nativo é muito rara. Falantes bi/multilíngues comumente têm uma língua em que se sentem mais confortáveis em certas situações. São as suas línguas de segurança. Portanto, tomamos como base a afirmação de Savedra $(1994 ; 2009)$ de que bi/multilinguismo é um fenômeno relativo, pois depende da forma como os códigos são adquiridos, do uso que fazem das línguas em comunidades de fala distintas e diferentes ambientes comunicativos e também da sua perda e/ou manutenção.

É bem evidente que aquisição, perda e manutenção de língua são palavras chave para o entendimento de bi/multilinguismo, e são os pontos mais básicos dos estudos de contato de línguas. Queremos, porém, salientar a importância da transmissão intergeracional nesse processo. Todos os aspectos que envolvem a transmissão linguística de genitores para filhos se relacionam com os fatores abordados acima. Refletindo e pesquisando sobre essas questões, concordamos com Pavlenko acerca das lacunas nos estudos que envolvem emoções e multilinguismo. Abordaremos esse tema com um estudo de caso que envolve o uso de emotion words na L2 do falante, e não na L1, contrariando as afirma-

\footnotetext{
${ }^{10}$ Indivíduos que mantêm suas L 1 como línguas dominantes e as percebem como mais emocionais podem espontaneamente inverter suas falas para L1 para discutir com os cônjuges ou para repreender os filhos e discipliná-los e para usar expressões consideradas tabus, palavrões e xingamentos para o máximo de efeito e satisfação.
} 
ções teóricas já mencionadas. No entanto, é importante deixar claro que não se trata de negar as teorias citadas, mas de enxergá-las sob outro ponto de vista e tentar enriquecer os estudos nesse campo.

\section{Delimitação do estudo}

Delimitaremos nosso estudo a uma cena cotidiana numa comunidade do interior, gravada em vídeo amador por um dos membros de um grupo de amigos e parentes. ${ }^{11} \mathrm{~A}$ filmagem não foi realizada por profissionais e tampouco por pesquisadores, o que acarreta vantagens e desvantagens inerentes. Começando pelas últimas, as imagens não têm boa resolução e há trechos cuja qualidade sonora é ruim, impossibilitando a compreensão de algumas falas. Contudo, tais trechos não interferem na nossa análise. Entre as vantagens, a principal é a naturalidade da situação, o que indica que os diálogos retratam a realidade do dia a dia da comunidade. Embora saibamos que a presença de uma câmera ou mesmo um gravador pode influenciar a atitude dos indivíduos em cena, como aponta Labov (2008) acerca do que ele denomina paradoxo do observador, acreditamos que no excerto em questão essa possível influência seja bastante reduzida, e não interferiu nos discursos apresentados.

Durante os diálogos que se apresentam, há marcas importantes de substrato de língua de imigração, a língua dos imigrantes italianos que ali se estabeleceram desde cerca de 1870. O traço que selecionamos para essa análise é lexical. Trata-se do uso de um xingamento - uma blasfêmia - típico de alguns falares italianos. Discutiremos a transmissão linguística intergeracional de expressões verbais relacionadas a momentos de emoção, em particular a blasfêmia "porco dio".

\section{Análise de linguagem emocional - cena cotidiana}

O extrato de vídeo-filmagem que propomos como base de nossa análise é amador, como antecipamos, e está disponível na rede social virtual Facebook. A cena retrata um grupo de pessoas tentando deslocar uma casa de madeira com a ajuda de dois pequenos tratores. Por imprudência ou imperícia, um dos tratoristas empurra o veículo com mais ímpeto e a casa sofre um dano. Então, um indivíduo, que chamamos de $\mathrm{H} 1$, se desespera e protesta veementemente, completamente transtornado. Os outros personagens são coadjuvantes e os nomeamos com as siglas H2, H3... e M1 (quem que registra o vídeo), M2 etc. A seguir, transcrevemos as falas dos personagens ${ }^{12}$, ilustradas por algumas imagens congeladas extraídas de toda a filmagem. Adotamos o formato mm:ss para as marcações dos tempos das falas, bem como das fotografias.

\footnotetext{
${ }^{11}$ A identificação de que sejam amigos e parentes entre si é intuitiva, baseada no conteúdo dos diálogos.

${ }^{12}$ Os seguintes critérios foram usados na transcrição: ININT = ininteligível; \{\}$=$ textos explicativos; []$=$ trechos sem certeza na audição; itálico = palavras ou expressões inusitadas; maiúsculas (fora do início de frase) $=$ ênfase na pronúncia (por exemplo, $\mathrm{R}=$ tepe; TE e DE $=[$ te $]$ e [de], em oposição a [t $\left.\int \mathrm{i}\right]$ e $\left[\mathrm{d} \int \mathrm{i}\right]$; negrito = ênfase na expressão "porco dio", aqui estudada.
} 
Figura 1. Cena em 00:00 - Trator escorando a casa

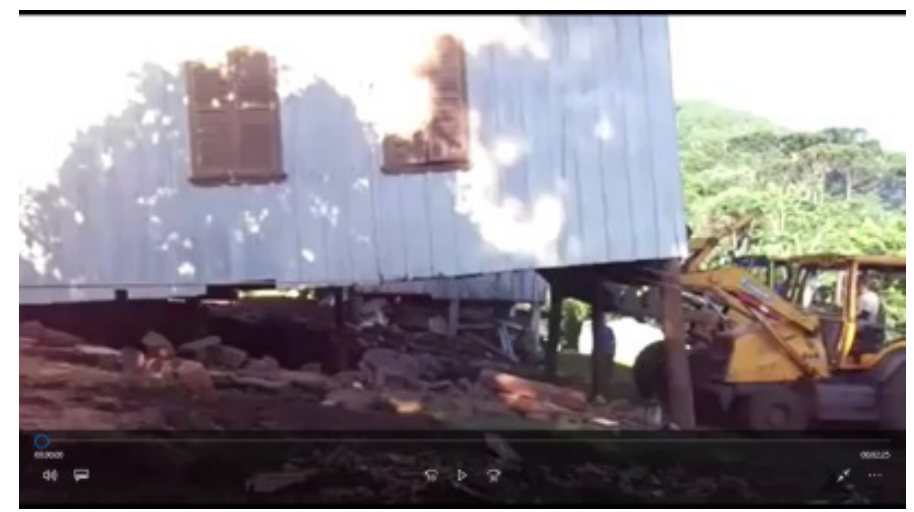

Fonte: Taliani buona gente (2016).

00:00 - \{início do excerto, sem falas $\}$

00:15 - H1: ôôôôoôôôôô! \{o informante grita longamente, para chamar a atenção\}

Figura 2. cena em 00:20 - Casa em movimento e o início dos danos

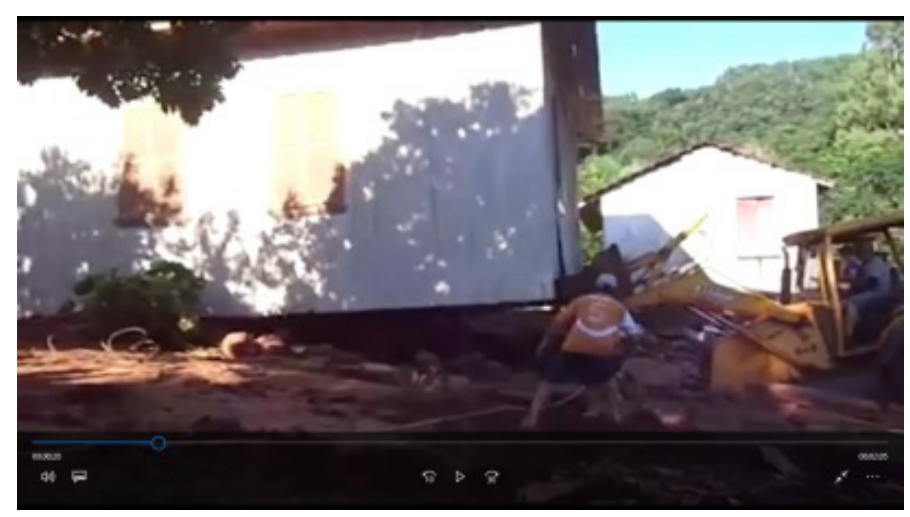

Fonte: Taliani buona gente (2016).

00:23 - H1: Nããão!!

00:26 - H1: Oh, caralho!

Figura 3. cena em 00:22 - Sequência dos danos na casa

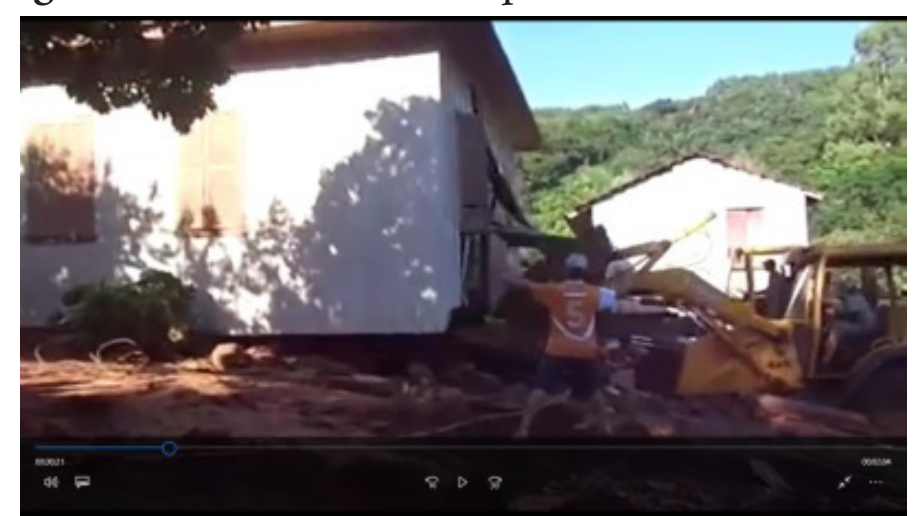

Fonte: Taliani buona gente (2016). 
Figura 4. Cena em 00:26 - Casa danificada

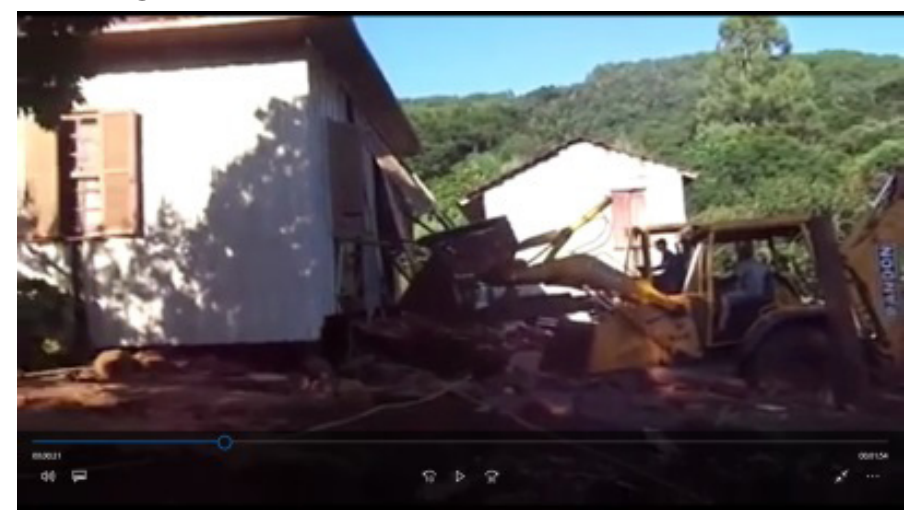

Fonte: Taliani buona gente (2016).

00:28 - M1: Mas num é, foi aqui atrás.

00:30 - H1: O Nico, muito Rápido...

00:32 - H1: Ei! O Nico, muito Rápido.

00:34 - H1: Tinha que ir com calma, genTE, nós tinha que controlá.

00:38 - H1: Ma calma!

Figura 5. Cena em 00:38 - Protagonista (H1) esbravejando, inconformado

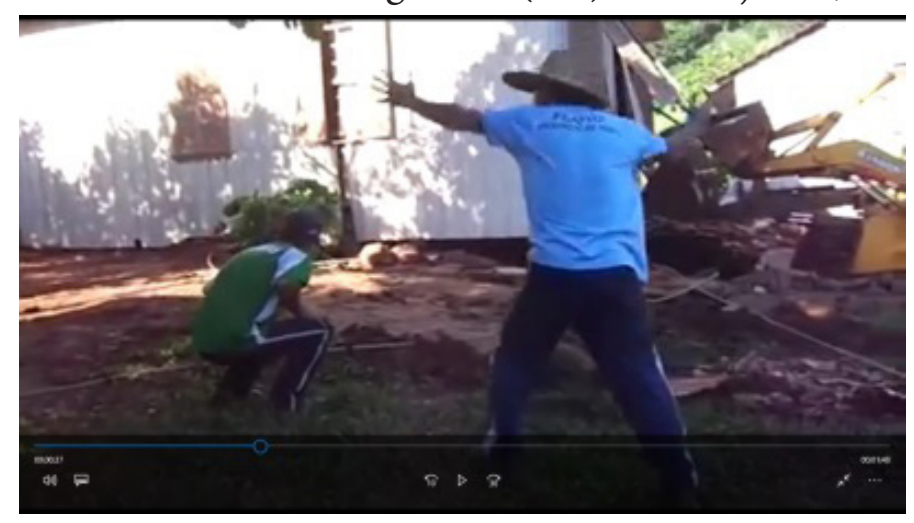

Fonte: Taliani buona gente (2016).

00:40 - H1: Ei! Mais calma!!

00:43 - H1: Tá lôco, genTE, muito Rápido! Isso aqui não é caminhão!

00:48 - H1: Porco dio!!

00:50 - H2: calma, calma, calma...

00:54 - H2: ININT

00:56 - H1: Ma oh, [genTE, amaRemo] as quatro, [se salvemo fora tuto] Ma calma, genTE, nós tinha que... \{falas de $\mathrm{H} 1$ e $\mathrm{H} 2$ sobrepostas - ININT\} 
01:05 - H1: Nós tinha que confirmá os três tudo.

01:10 - H1: Tá lôco, me arranca fora até o jerico aqui!

01:18 - M1: O Nico só foi pra traz porque a casa ia pra cima, foram eles que empuRaram.

01:23 - H1: Ma não, mãe, eles aqui parece que tão caRegando cascalho, tchê!

01:27 - M1: Para, paiê!

01:28 - M1: Foi, essa casa vai ser desmanchado mesmo.

01:30 - H1: Não, eu sei, ma tem que ter calma, oh, eu tava lá desamaRando, me puxaram até a solda... Do jerico!

01:37 - M2: ININT

01:38 - H1: Porco dio!!

01:41 - H1: Tinha que ir como nós combinamo! GenTE, calma, vamo tirar a solda, vamo ficá um aqui outro lá em cima, o Nico... O Nico nem puxou. Vocês empuRaram direto.

01:50 - H3: ININT

01:53 - H1: Claaaro, nós tinha que abaixá ela, com calma!

02:00 - H1: Ma tá bom, tá bom, não aconteceu nada.

Figura 6. Cena em 02:02 - Protagonista gesticulando, já mais calmo

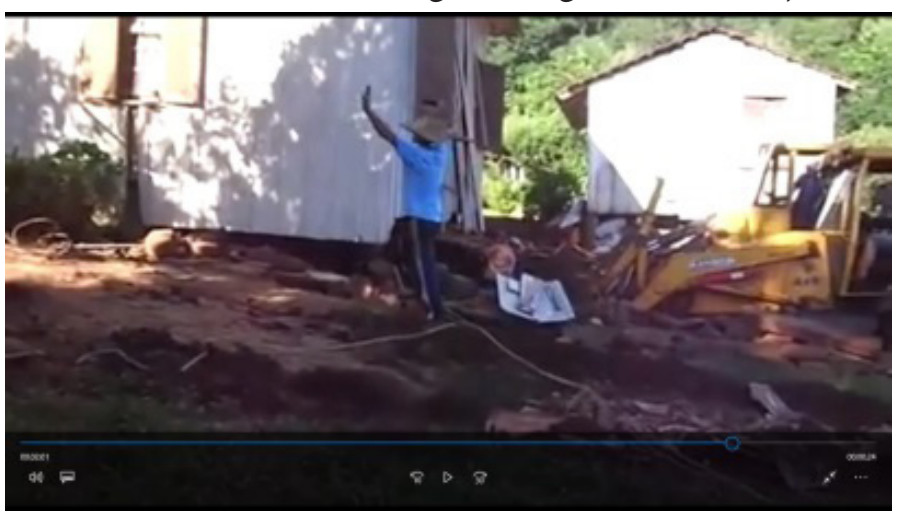

Fonte: Taliani buona gente (2016).

\section{2:02 - M2: ININT}

02:05 - H1: Dio porco, dio porco!!!

02:07 - H1: Muita pressa, genTE!

02:10 - H1: Ma tá bom, oh! Não foi o pior, eu achava que ela ia rodá! Quando que eu vi que estorô tudo, ah, eu disse: ela vai empinotá!

02:17 - H3: ININT 
02:20 - H1: Não, mas aí só suspenDE...

02:22 - H1: Oh, tu sabe que o Nico nem é... O Nico teve que fugi?

02:24 - \{fim do excerto $\}$

As conversas são mantidas em uma das variedades do Português Brasileiro (PB), e algumas falas apresentam fortes marcas de substrato fonético do dialeto vêneto, como o tepe em palavras como 'empurraram' ([ẽpu'rarãw], 0:01:21; 0:01:48), 'carregando ([kare'gãdu]), 0:01:24) e 'desamarrando' ([dezama'rãdu]), 0:01:33). Há também outras marcas fonéticas características da fala local, tais como a pronúncia forte dos fonemas linguodentais surdos ([te]) e sonoros ([de]) em fim de sílaba (['3ẽte]), 0:00:36; 0:00:44; 0:01:00; 0:01:43 e ([sus'pẽde]), 0:02:20), diferentemente do que ocorre na maioria das variedades brasileiras, em que a pronúncia nessa situação é africada (['3ẽt $\left.\int i\right]$ ) e [sus'pẽdfi]) e fraca. Apenas a título de esclarecimento, os casos de tepe não são alofones do fonema $/ \mathrm{h} /$, ao passo que as linguodentais surdas e sonoras [te] e [de] são alofones, respectivamente, de [t $\mathrm{fi}]$ e $\left[\mathrm{d} \int \mathrm{i}\right]$. Não é nosso interesse, entretanto, tratar de fenômenos fonológicos neste estudo. Com essas considerações pretendemos apenas contextualizar a situação. $\mathrm{O}$ caso aqui estudado está no plano lexical, envolve blasfêmia, o insulto a entidades religiosas como forma de xingamento, relativamente comum em algumas línguas italianas, sobretudo o vêneto. ${ }^{13}$

\section{O objeto do estudo}

Chegamos, então, ao ponto principal de nossa análise, o uso dos xingamentos e expressões consideradas tabus, entre as quais certamente se incluem as blasfêmias. Durante os pouco mais de dois minutos de filmagem, o protagonista da cena faz uso da expressão "porco dio" (ou "dio porco") ${ }^{14}$ em três ocasiões (0:00:49; 0:01:38; 0:02:04), momentos de profunda indignação com o infortúnio acontecido. São momentos de forte emoção. Para os falantes italianos, a locução "porco dio" é uma expressão cristalizada, com sentido único. Seu significado é a ofensa ou insulto ao sagrado motivado por uma situação desconfortável, irritante, desagradável. Seu significante é a blasfêmia que associa Deus (Dio) a algo sujo, representado pelo porco.

Mesmo sem conhecer os participantes e sem nos envolvermos diretamente na situação, sabemos que a L1 do grupo é o PB, evidentemente uma variedade de uma região influenciada por substratos de dialeto vêneto. Embora haja um processo sistemático

\footnotetext{
${ }^{13}$ A respeito do uso histórico de xingamentos e blasfêmias em línguas italianas, ver Burke (1989).

${ }^{14} \mathrm{O}$ protagonista da cena utiliza ambas as expressões, as quais têm o mesmo valor semântico. Portanto, por simplificação, vamos nos referir somente a uma delas.
} 
de valorização das línguas minoritárias e de imigração no Brasil, o talian, a variedade da língua vêneta falada por grupos de descendentes de italianos, não é mais a L1 da grande maioria dos habitantes locais, limitando-se a alguns idosos de comunidades rurais (FROSI, 2013).

A blasfêmia “porco dio", proferida em três momentos, um deles com repetição, aponta para um code-switching motivado por aspectos emocionais, que remetem à necessidade de "máximo efeito e satisfação" (PAVLENKO, 2012, p. 461). À diferença dos estudos de Dewaele e Pavlenko, demonstrados em Pavlenko (2012), não se trata aqui de um usuário de uma certa L2 que usa sua própria L1 em momentos de emoção. Trata-se de um caso de transmissão intergeracional de marcas de língua, que penetraram na L1 do falante como substratos. Então, não se trata de uma opção por L1 em momento de forte emoção, mas da repetição de uma expressão ouvida em ambientes comunicativos íntimos e transmitida pelos ancestrais, e que mais bem se adequa àquela situação.

Identificamos uma ligação entre linguagem emocional e substratos que pode ser estudada em perspectiva sincrônica, como um code-switching, em perspectiva diacrônica, como parte do processo de language shift, e à luz da semântica. Numa observação mais superficial, temos um caso de substrato linguístico, uma expressão específica transmitida pelos ancestrais imigrantes às gerações seguintes. As razões que levam à manutenção dessa expressão têm relação direta com a linguagem emocional - trata-se de uma emotion word. É uma expressão usada em situações de contrariedade, raiva, indignação, momentos de intimidade. Vejamos a seguir três perspectivas em que o caso em questão pode ser estudado.

\section{Três perspectivas de estudo}

Tomamos como base teórica de estudo a literatura a respeito de linguagem emocional. A partir disso, podemos analisar o caso sob três perspectivas, as quais não são excludentes. Podem, porém, ser independentes ou complementares, de acordo com o objetivo e a abordagem do trabalho.

Sincronicamente, podemos dizer que se trata de code-switching ${ }^{15}$ (GUMPERZ; HYMES, 1986) para suprir uma necessidade vocabular (GROSJEAN, 1982). Porém, podemos considerar que se refira a um caso particular de code-switching, na medida em que o falante/informante é um sujeito monolíngue cuja língua mantém substratos da L1 de seus ancestrais e de outros indivíduos do passado de sua comunidade. Em outras pala-

\footnotetext{
${ }^{15}$ Por uma questão de simplificação, preferimos o termo mais genérico code-switching para essa situação, embora alguns autores possam-na considerar um caso de code-mixing.
} 
vras, não se trata de um caso canônico de code-switching, aqueles em que o falante é bi ou multilíngue e alterna códigos que domina.

Em perspectiva diacrônica, trata-se de parte de um processo de language shift (WEINREICH, 1968 [1953]; WINFORD, 2003; ROMAINE, 2010). As gerações mais jovens, descendentes dos imigrantes, mudaram o uso da língua habitual - a L1 dos imigrantes - para outra, a língua nacional/oficial do país receptor, que era/é a língua dominante. Todavia, pelo longo tempo em que essas comunidades de descendentes de italianos se mantiveram quase isoladas, a transmissão linguística não foi influenciada pela língua nacional. O contato foi acontecendo paulatinamente e o período de atrição ${ }^{16}$ foi mais longo. Assim, notamos ainda hoje marcas fortes de substrato da língua dos imigrantes, diferentemente do que ocorre em situações de imigração do tipo urbana. O processo de morte da língua dos imigrantes italianos brasileiros ainda não aconteceu, embora tudo tenha conspirado até recentemente para que tivesse ocorrido (FROSI, 2013). O Talian ainda está vivo, mas não é a L1 dos mais jovens. Com as recentes políticas públicas de valorização das línguas minoritárias e a partir do Decreto 7387/2010 (criação do Inventário Nacional da Diversidade Linguística do Brasil), o Instituto do Patrimônio Histórico Nacional (IPHAN) reconheceu oficialmente o Talian como Referência Cultural Brasileira ao lado de outras duas línguas indígenas, o Asurini do Trocará e o Guarani Mbyá. Note-se que entre as reconhecidas, o Talian é única língua de imigração.

É evidente que a fala dos principais participantes da cena filmada é fortemente influenciada foneticamente por falares italianos. De fato, em casos de language shift a língua dominante "pode sofrer variações sistemáticas com consequentes mudanças, influenciadas pelas línguas que foram perdidas" (SAVEDRA; GAIO; CARLOS NETO, 2015, p. $75)$. Nas falas identificadas no vídeo, observamos marcas importantes, frutos dessa influência da língua de imigração. Destacamos o tepe, marca fonológica característica do falar da língua vêneta, proveniente da região italiana do Vêneto. Não podemos afirmar, porém, com base somente nesse excerto de vídeo, que a expressão "porco dio" seja uma marca lexical regional motivadora de mudança, como exemplo da terceira onda dos estudos de variação linguística (ECKERT, 2000; 2012). É mais plausível admitir que seja uma variedade socioletal.

Vejamos agora uma perspectiva semântica. Como já dissemos, a expressão italiana “porco dio” examinada per se é uma blasfêmia. No caso específico, associa Deus (Dio) a sujeira, imundície, representada pelo porco. Nas interações, é utilizada em situações de

\footnotetext{
${ }^{16}$ Attrition no original em inglês. Tomamos a tradução de Couto (2009, p. 85): "processo gradual de perda
} de domínios de uso, de falantes e de material linguístico”. 
contrariedade, raiva, indignação, surpresa. Conceitualmente seu significado é de um xingamento, e seu significante corresponde à reação a um aborrecimento, uma agrura, uma situação desagradável. O sentido de ofensa ao sagrado só é compreendido como tal pelo conhecimento semântico prévio dos termos "dio" e "porco".

Como já vimos, ao longo das gerações, o processo de language shift foi tomando lugar motivado por várias razões, inclusive ideológicas, que não nos cabe discutir aqui. ${ }^{17}$ Alguns traços da língua de imigração permaneceram como substrato e exemplificamos casos do plano fonológico e lexical. Com o processo de language shift completamente implantado, a língua de imigração passa a ser L2 (quando existe), ou mantém-se apenas por lembranças de expressões específicas, geralmente ligadas à intimidade da família ou da coletividade. Nesse momento, para as novas gerações, a expressão "porco dio" mantém seu significante original, mas perde seu significado, que se transforma em um xingamento, uma palavra de baixo calão. "Dio" não representa o sagrado; a imagem acústica de "dio" (['dio]), para as novas gerações, não remete ao sagrado porque em sua L1 a mesma entidade é representada por outro som cuja grafia é 'deus' (['dews]). O termo "porco" sofreria as mesmas consequências, não fosse a coincidência de ser representado morfofonologicamente de maneira semelhante na língua dominante. Porém, a expressão "porco dio" só tem sentido completo se pronunciada como um único vocábulo. Então, a questão da coincidência léxico-morfológico-semântica não exerce interferência na sua percepção.

Sendo assim, é plausível supor que o peso semântico da expressão "porco dio", transmitida através das gerações, tenha sofrido alteração. Deixou de ser blasfêmia, incomum ou inexistente em $\mathrm{PB}$ ao menos nessas situações, e passou a ser um xingamento, uma expressão a ser usada em casos de contrariedade, talvez nem mesmo com o peso de uma interjeição chula como "caralho" ou "merda”. Uma observação in loco poderia levar o pesquisador a conclusões mais efetivas.

\section{Considerações finais}

A literatura sobre linguagem emocional costuma tratar de sujeitos bi/multilíngues e seus usos de L1 em momentos de emoção, ou de intimidade, tais como as conversas íntimas com o cônjuge, ou a repreensão aos filhos. Neste estudo, mostramos um caso de uso da língua de ancestrais imigrantes italianos em momento de forte apelo emocional. $\mathrm{O}$ caso evidencia as lacunas existentes nos estudos da relação entre língua e emoção, apontadas por Pavlenko (2012).

\footnotetext{
${ }^{17}$ Frosi (2013) discute a identidade étnica e linguística do ítalo-brasileiro do sul do país e esclarece essa questão.
} 
Neste artigo, a partir da ilustração de um caso de transmissão linguístico-cultural, mostramos o uso de uma expressão substrática de uma língua de imigração na língua dominante e sua relação com o processo de transculturação ${ }^{18}$, que aponta para a condição de transculturalidade de uma população - nas palavras de Welsch (1999), culturas que se interpenetram. $\mathrm{O}$ caso de transmissão linguística intergeracional aqui estudado assinala a importância da relação existente entre língua e emoção, indicando assim um caminho para outros estudos dessa natureza, pois, como afirma Pavlenko (2012), essa relação carece de pesquisas.

$\mathrm{O}$ caso estudado se restringe a uma região do interior ${ }^{19}$ cujos traços linguísticos, manifestados no excerto, demonstram forte influência da língua dos imigrantes italianos que ocuparam o local. Portanto, trata-se de um caso de legado cultural de um grupo de imigrantes majoritário, transmitido através das gerações.

Analisamos uma demonstração de como pode funcionar o processo de transmissão linguístico-cultural intergeracional. Em ambientes urbanos brasileiros, sobretudo nas regiões sul e sudeste, há dificuldade em isolar casos, uma vez que as influências vêm de diversas culturas. Em longo prazo, o resultado desse processo de transculturação é um sincretismo cultural (CANEVACCI, 2004) tipicamente brasileiro: culturas que se absorvem, se entrelaçam e se recriam num continuum.

O Brasil de hoje é uma sociedade plurilíngue, multiétnica e miscigenada entre povos oriundos de diversas partes do mundo. Há nela elementos culturais e linguísticos de suas origens, provenientes de diferentes situações de contato (SAVEDRA; GAIO; CARLOS NETO, 2015, p. 139), que são incorporados às demais culturas, criando a sua identidade própria. $\mathrm{O}$ papel da transmissão linguístico-cultural intergeracional tem particular importância na formação dessa identidade transcultural. Certamente, o componente italiano em todo esse processo é bastante relevante, dada a quantidade elevada de imigrantes provenientes daquele país.

\section{Referências}

AVERILL, J. R. Anger and Agression: an Essay on Emotion. New York: Springer-Verlag, 1982

BURKE, P. The historical anthropology of early modern Italy. Essays on perception and communication. Cambridge: Cambridge University Press, 1989. . Cultural Hybridity. Cambridge: Polity Press, 2009

\footnotetext{
${ }^{18}$ O termo "transculturação" aparece pela primeira vez em 1940, proposto pelo intelectual cubano Fernando Ortiz (1999 [1940]) para explicar a formação cultural do povo da ilha de Cuba.

${ }^{19} \mathrm{O}$ excerto do vídeo não é suficiente para precisar tal região. De todo modo, essa imprecisão não interfere na análise proposta
} 
CANEVACCI, M. Sincretismi. Esplorazioni diasporiche sulle ibridazioni culturali. Milano: Costlan editori, 2004

COUTO, H. H. Linguística, ecologia e ecolinguística. São Paulo: Contexto, 2009

CROCI, F. A Imigração no Brasil. In: MELLO, H.; ALTENHOFEN, C. V.; RASO, T. Os contatos linguísticos no Brasil. Belo Horizonte: Editora da UFMG, 2011. p. 73-120.

DEWAELE, J.; PAVLENKO, A. Emotion Vocabulary in Interlanguage. Language Learning, v. 52, n. 2, p. 263-322, 2002.

DEWAELE, J. Emotions in Multiple Languages. Basingstoke: Palgrave Macmillan, 2013.

ECKERT, P. Linguistic variation as social practice. Oxford: Blackwell, 2000.

. Three Waves of Variation Study: The Emergence of Meaning in the Study of Sociolinguistic Variation. Annual Review of Anthropology, v. 41, p. 87-100, jun. 2012.

FROSI, V. M. A Identidade Étnica e Linguística do Ítalo-Brasileiro: sua constituição e reconstrução. SIGNUM, Londrina, v. 16, n. 2, p. 101-124, 2013.

GROSJEAN, F. Life with Two Languages: An Introduction to Bilingualism. Cambridge, Mass: Harvard University Press, 1982.

GUMPERZ, J. J.; HYMES, D. Directions in Sociolinguistics: The ethnography of communication. Oxford: Blackwell, 1986.

HARKINS, J.; WIERZBICKA, A. (Eds.). Emotions in Crosslinguistic Perspective. Berlin: Mouton de Gruyter, 2001.

LABOV, W. Padrões Sociolinguísticos. Tradução de Marcos Bagno, Maria Marta Pereira Scherre e Caroline Rodrigues Cardoso. São Paulo: Parábola, 2008.

ORTIZ, F. Contrapunteo cubano del tabaco y el azúcar. Madrid: EditoCubaEspaña, 1999 [1940].

PAVLENKO, A. Multilingualism and emotions. In: MARTIN-JONES, M.; BLACKLEDGE, A.; CREESE, A. The Routledge Handbook of Multilingualism. Abingdon: Routledge, 2012. p. 454-469.

ROMAINE, S. Contact and language death. In: HICKEY, R. The handbook of language contact. Oxford: Blackwell, 2010. p. 320-339.

SAVEDRA, M. M. G. Bilingüismo e bilingualidade: O tempo passado no discurso em língua portuguesa e alemã. 1994. 436 f. Tese (Doutorado) - Faculdade de Letras, Universidade Federal do Rio de Janeiro, 1994. 
. Bilinguismo e bilingualidade: uma nova proposta conceitual. In: SAVEDRA, M. M. G.; SALGADO, A. C. P. (Org.). Sociolinguística no Brasil: Uma contribuição dos estudos sobre línguas em/de contato. Rio de Janeiro: 7Letras, 2009. p. 121-140.

SAVEDRA, M. M. G.; GAIO, M. L. M.; CARLOS NETO, M. E. Contato linguístico e imigração no Brasil: fenômenos de manutenção/revitalização, language shift e codeswitching. Veredas, v. 19, p. 71-91, 2015.

Taliani buona gente. Bepi e piero drio mudar na casa de posto! 2016.

Disponível em: https://www.facebook.com/TalianiBuonaGente/videos/ vb.278365595609003/807926089319615/?type=2\&theater. Acesso em: 23 jan. 2017.

WEINREICH, U. Languages in Contact: Findings and Problems. The Hague, Netherlands: Mouton Publishers \& Co. N. V., 1968 [1953].

WELSCH,W.Transculturality-thePuzzlingForm ofCultures Today.FEATHERSTONE, M.; LASH, S. (Ed.). Spaces of Culture: City, Nation, World. London: Sage, 1999. p. 194213.

WINFORD, D. An introduction to contact linguistics. Oxford: Blackwell, 2003.

Submetido em: 26/01/2017

Aceito em: 05/04/2017 